\title{
A cloudy fuzzy economic order quantity model for imperfect-quality items with allowable proportionate discounts
}

\author{
Sujit Kumar De ${ }^{1} \cdot$ Gour Chandra Mahata ${ }^{2}$
}

Received: 30 July 2018 / Accepted: 1 March 2019 / Published online: 8 March 2019

(c) The Author(s) 2019

\begin{abstract}
In the traditional economic order quantity/economic production quantity model, most of the items considered are of perfect type. But this situation rarely takes place in practice. Thus, in this paper, an economic order quantity model with imperfectquality items is developed. $100 \%$ screening process is performed, and the items of imperfect quality are sold as a single batch. A proportionate rate of discount for the items of imperfect quality has also been studied. Moreover, a case study has been incorporated to comprehend the model. To nullify the issues of non-random uncertainties of demand rate in business scenario, cloudy fuzzy method has been utilized here. Numerical study reveals that cloud model along with its new defuzzification methods can give maximum profit of the model all the time instead of deterministic ones. Finally, sensitivity analysis and graphical illustrations are made to justify the novelty of the model.
\end{abstract}

Keywords EOQ $\cdot$ Screening cost $\cdot$ Imperfect quality $\cdot$ Cloudy fuzzy number $\cdot$ New defuzzification method $\cdot$ Optimization

\section{Introduction}

In the beginning of twentieth century, Harris (1913) first studied a classical EOQ model. Wilson (1934) contributed a statistical approach to find order points where demand rate is assumed to be constant. Since then, a great amount of effort has been paid by several researchers in formulating more realistic lot sizing model by considering imperfect-quality items. As the classical EOQ model is oldest and simplest, the academicians as well as the business persons are experiencing with some new ideas that genuinely improve the weaknesses of the existing research. In fact, a common assumption of traditional EOQ model was that all produced items would be of perfect quality. But this assumption was not logical for several reasons, including faulty production process, failure in the process of transportation, instant power cut during production, etc. Thus, it is difficult to produce

Gour Chandra Mahata

gcmahata.skbu@gmail.com; gourmahata@yahoo.co.in

1 Department of Mathematics (UG \& PG), Midnapore College (Autonomous), P.O. - Midnapore, Dist. Paschim Medinipur, West Bengal 721101, India

2 Department of Mathematics, Sidho-Kanho-Birsha University, P.O. - Purulia Sainik School, Ranchi Road, Purulia, West Bengal 723104, India or purchase items with $100 \%$ perfect type. Therefore, the screening of lot of items becomes emergent. These practices have received attention from many researchers, and many authors have addressed to this issue of lot sizing decision for imperfect-quality items recent times. Consequently, a vast literature on imperfect type inventory production model has come up, by generalizing the EOQ model in numerous directions.

Karlin (1958) was one of the first to address on the EOQ model of imperfect type items. He studied the assumptions underlying the structure of the inventory cost components and presented three single-stage newsvendor models to characterize the optimal ordering policy under random supply. Porteus (1986) incorporated the effect of defective items into the original EOQ model. For the production process, he introduced ' $p$ ' as the percentage of defective and also assumed that the percentage of defective random variable $p$ obeys the geometric distribution. Rossenblatt and Lee (1986) assumed that the time between the beginnings of the production run until the process goes out of control is exponential and that defective items can be reworked instantaneously at a low cost, and they conclude that the presence of defective products motivates customers to buy smaller lot sizes. Subsequently, Lee and Rossenblatt (1987) considered process inspection during the production run so that the shift to outof-control state can be detected and restoration made earlier. 
A joint lot sizing and inspection policy is studied under an EOQ model where random proportions of units are defective. These units can be discovered only through expensive inspections. Hence, the problem is bivariate; both normal lot size and fractional lot size for inspection are to be chosen. Gerchak et al. (1988) analyzed a single-period production problem where the production process was characterized by uncertain demand and variable yield. The single-period model was then extended to $n$-period model. Cheng (1991) proposed an EOQ model with demand dependent on unit production cost and imperfect production processes. He formulated this inventory decision problem as a geometric program (GP), and it is solved to obtain closed-form optimal solutions. Urban (1992) modeled the defect rate of a production process as a function of the run time length and derived closed-form solutions for the model. This model accounted for either positive or negative learning effects in production process. Ben-Daya (1999) proposed multistage lot sizing models for imperfect production processes. Rezaei (2005) extended the model by assuming shortages in a cycle resulting from defective items are completely backordered in the beginning of each cycle and he also determined an optimal lot size of the order and the backorder. Salameh and Jaber (2000) developed an extended EOQ model where imperfectquality items are salvaged at a constant discounted price. Two years later, Goyal and Cárdenas-Barrón (2002) provided a new simple approach to the inventory model of Salameh and Jaber (2000). Chan et al. (2003) presented a new EPQ model in which three different situations of reselling, reworking, or rejecting imperfect products are incorporated.

Afterward, Papachristos and Konstantaras (2006) presented an extension to the work of Salameh and Jaber (2000). In their model, they considered another situation where the retailer sells these defective items at the end of replenishment interval but not at the end of screening process. Considering the unavoidable shortages in real-life situations, Eroglu and Ozdemir (2007) developed an EOQ inventory model with a random percentage of defective products every cycle. In their paper, shortages are assumed to be backordered, and the research results show that an increase in rate of defective leads to a decrease in the optimal total profit. Maddah and Jaber (2008) revisited the inventory model introduced by Salameh and Jaber (2000) and also given a new version to the EOQ model with imperfect items by considering that several batches of defective items are delivered in a single lot. Cárdenas-Barrón (2009) developed an EPQ model with planed backorders and reworking of imperfect items from the perspective of singlestage manufacturing system. Khan et al. (2011) provided a comprehensive literature review for the extensions of EOQ model with imperfect products. Meanwhile, Sarkar (2012) investigated an EOQ model in which defective products are assumed to occur every cycle under dependent demand and progressive payment scheme. Jaber et al. (2014) proposed a new variant for the inventory model of Salameh and Jaber (2000) by considering options of buying new ones or repairing imperfect ones for defective products. Taleizadeh et al. (2016) presented an EOQ model in which defective items are sent to a local repair store and the shortages are assumed to be partial backordered, which extended the EOQ inventory model discussed by Jaber et al. (2014). In most recent years, Pal and Mahapatra (2017) developed an inventory model with imperfect products for a three-level supply chain, and three different ways of dealing with defective products were investigated in their model. From a sustainable point of view, Kazemi et al. (2018) studied EOQ model by considering carbon emissions and products with imperfect quality. Aghili and Hoseinabadi (2017) studied over the repairable items under fuzzy environment. The pricing and ordering policies of imperfect items in a supply chain have been developed by Taleizadeh et al. (2015). Also, Mondal et al. (2013) considered the inflation of money in production-repairing inventory model in fuzzy rough systems. For the cases of pharmacological products Taleizadeh and Noori-daryan $(2015,2016)$ discussed over rework process of the items considering game theoretic approach in a supply chain.

Moreover, the essential and impractical assumptions are that all the inventory scenarios occur under a certain and deterministic environment. But in today's competitive and dynamic business world, it is not possible to access all the necessary information. Hence, the information related to the inventory system is not well-defined as assumed in the traditional models. One of the effective methods to overcome these drawbacks is using fuzzy set theory, developed by Zadeh (1965), making possible to transform ill-defined information to powerful mathematical expressions.

For more than half of a century, fuzzy set theory has been gaining a noticeable momentum by applying in many fields of operations research (Gholizadeh and Shekarian 2012; Shekarian and Gholizadeh 2013; Shekarian et al. 2016a) as well as inventory management (Shekarian et al. 2016b, c). Numerous variants and extensions of fuzzy inventory models have been offered on the evolution of classical inventory models including news vendor, reorder point, inventory control, joint economic lot size models, etc. Inventory management requires demand forecasts as well as parameters for inventory-related costs such as holding, replenishment, shortages and backorders (Kahraman et al. 2006). As the precise estimations of these model attributes are often difficult in practice, the inventory-related data can be calibrated using the fuzzy techniques, which facilitates dealing with the real-world cases in a more proper way.

Some notable recent works in fuzzy system like Das et al. (2015) presented an integrated production inventory model under interactive fuzzy credit period for deteriorating item with several markets. Due to randomness and fuzziness, 
Kumar and Goswami (2015) and Mahata and Goswami (2013) proposed a fuzzy random EPQ model for imperfectquality items with possibility and necessity constraints. Currently, Mahata (2017) investigated the learning effect of the unit production time on optimal lot size for the imperfect production process with partial backlogging of shortage quantity in fuzzy random environments. He assumed that the setup cost, the average holding cost, the backorder cost, the raw material cost, and the labor cost are characterized as fuzzy variables, and the elapsed time until the machine shifts from "in-control" state to "out-of-control" state is characterized as a fuzzy random variable. Articles on learning effect have been discussed wisely by Shekarian et al. (2016b). Alternatively, De and Beg (2016a, b) introduced dense fuzzy approach to capture the degree of learning experiences recent times. After that, the idea of dense fuzzy number was extended by De and Mahata (2017). To do this, they have developed a cloud-type fuzzy number incorporating the inventory cycle time to the measure of fuzziness. To resolve the difficulties and to defuzzify the cloud-type fuzzy number, they invented a new defuzzification method also. Recently, Karmakar et al. (2017) first established a pollution-sensitive dense fuzzy economic production quantity model with cycle time-dependent production rate. Concurrently, De and Sana (2015) developed a backlogging model implementing a phi coefficient test for pentagonal fuzzy number. Chakraborty et al. (2015) investigated a supply chain model with stockdependent demand under fuzzy random and bi-fuzzy environments. Beyond this, researchers like De and Sana (2013), De et al. (2014), Karmakar et al. (2015), etc., have kept a remarkable destination over the fuzzy backlogging models.

From the above study, it is seen that not a single article for defective items has been developed utilizing the concept of non-randomly uncertainty over demand rate as well as order quantity for cloudy fuzzy environment. Thus, an inventory model with imperfect quantity items with allowable proportionate discounts has been discussed over here. A new defuzzification method has been utilized to optimize the model. Based on new approach, numerical and graphical illustrations are made and end with a sensitivity analysis of the several parameters as well.

\section{Preliminary concept (De and Beg 2016a, b; De and Mahata 2017)}

Here few essential definitions and formulas which have been used frequently for solving the proposed model are discussed.

\section{Normalized general triangular fuzzy number (NGTFN)}

Let $\tilde{a}$ be a NGTFN having the form $\tilde{a}=\left(a_{1}, a_{2}, a_{3}\right)$. Then its membership function is defined by

$\mu(a)= \begin{cases}0 & \text { if } a\left\langle a_{1} \text { and } a\right\rangle a_{2} \\ \frac{a-a_{1}-a_{1}}{a_{2}} & \text { if } a_{1} \leq a \leq a_{2} \\ \frac{a_{3}-d}{a_{3}-a_{2}} & \text { if } a_{2} \leq a \leq a_{3}\end{cases}$

Now, the left and right $\alpha$-cuts of $\mu(\tilde{a})$ are given by

$L(\alpha)=a_{1}+\left(a_{2}-a_{1}\right) \alpha$ and $R(\alpha)=a_{3}-\left(a_{3}-a_{2}\right) \alpha$

Note that the measures of fuzziness can be obtained from the following formula:

\section{Yager's (1981) ranking index}

If $L(\alpha)$ and $R(\alpha)$ are the left and right $\alpha$-cuts of a fuzzy number $\tilde{a}$, then the defuzzification rule under Yager's ranking index is given by

$I(\tilde{a})=\frac{1}{2} \int_{0}^{1}[L(\alpha)+R(\alpha)] \mathrm{d} \alpha=\frac{1}{4}\left(a_{1}+2 a_{2}+a_{3}\right)$.

Note that the measures of fuzziness (degree of fuzziness $d_{\mathrm{f}}$ ) can be obtained from the formula $d_{\mathrm{f}}=\frac{U_{\mathrm{b}}-L_{\mathrm{b}}}{2 m}$, where $L_{\mathrm{b}}$ and $U_{\mathrm{b}}$ are the lower bounds and upper bounds of the fuzzy numbers, respectively, and $m$ being their respective mode.

\section{Cloudy normalized triangular fuzzy number (CNTFN)}

A fuzzy number of the form $\tilde{A}=a_{1}, a_{2}, a_{3}$ is said to be cloudy triangular fuzzy number if after an infinite time the set itself converges to a crisp singleton. This means that, as time $t$ tends to infinity, both $a_{1}, a_{3} \rightarrow a_{2}$. Let us consider the fuzzy number

$\tilde{A}=\left\langle a_{2}\left(1-\frac{\rho}{1+t}\right), a_{2}, a_{2}\left(1+\frac{\sigma}{1+t}\right)\right\rangle, \quad$ for $0<\rho, \sigma<1$

Note that $\lim _{t \rightarrow \infty} a_{2}\left(1-\frac{\rho}{1+t}\right)=a_{2}$ and $\lim _{t \rightarrow \infty} a_{2}\left(1+\frac{\sigma}{1+t}\right)=a_{2}$,
so $\tilde{A} \rightarrow\left\{a_{2}\right\}$.

Then the membership functions for $0 \leq t$ is as follows:

$$
\mu(x, t)= \begin{cases}0 & \text { if } x\left\langle a_{2}\left(1-\frac{\rho}{1+t}\right) \text { and } x\right\rangle a_{2}\left(1+\frac{\sigma}{1+t}\right) \\ \left\{\frac{x-a_{2}\left(1-\frac{\rho}{1+t}\right)}{\frac{\rho a_{2}}{1+t}}\right\} & \text { if } a_{2}\left(1-\frac{\rho}{1+t}\right) \leq x \leq a_{2} \\ \left\{\frac{a_{2}\left(1+\frac{\sigma}{1+t}\right)-x}{\frac{\sigma a_{2}}{1+t}}\right\} & \text { if } a_{2} \leq x \leq a_{2}\left(1+\frac{\sigma}{1+t}\right)\end{cases}
$$




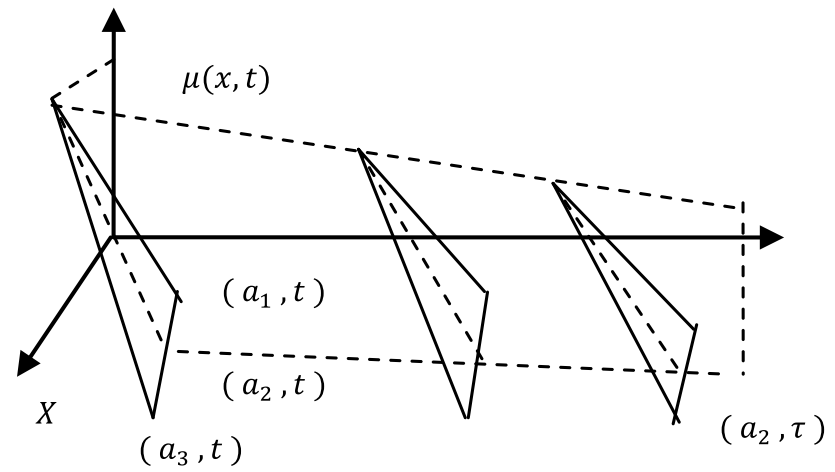

Fig. 1 Membership function of CNTFN

The graphical representation of CNTFN (Fig. 1) can be obtained as follows:

\section{Ranking index over CNTFN}

Let us take left and right $\alpha$-cuts of $\mu(x, t)$ from (5) noted as $L(\alpha, t)$ and $R(\alpha, t)$ respectively. Then the defuzzification formula under time extension of Yager's ranking index is given by

$I(\tilde{A})=\frac{1}{2 T} \iint_{\alpha=0, t=0}^{\alpha=1, t=T}\left\{L^{-1}(\alpha, t)+R^{-1}(\alpha, t)\right\} \mathrm{d} \alpha \mathrm{d} t$.

Note that, $\alpha$ and $t$ are independent variables.

Let $\tilde{A}$ be a CNTFN stated in (4) with its membership function (5). Now utilizing (5) the left and right $\alpha$-cuts of $\mu(x, t)$ are given by

$$
\begin{aligned}
& L^{-1}(\alpha, t)=a_{2}\left(1-\frac{\rho}{1+t}+\frac{\rho \alpha}{1+t}\right) \\
& \quad \text { and } R^{-1}(\alpha, t)=a_{2}\left(1+\frac{\sigma}{1+t}-\frac{\sigma \alpha}{1+t}\right)
\end{aligned}
$$

Thus (6) gives

$$
I(\tilde{A})=\frac{a_{2}}{2 T}\left[2 T+\frac{\sigma-\rho}{2} \log (1+T)\right]
$$

Again (8) can be rewritten as $I(\tilde{A})=a_{2}\left[1+\frac{\sigma-\rho}{4} \frac{\log (1+T)}{T}\right]$. Obviously, $\lim _{T \rightarrow \infty} \frac{\log (1+T)}{T}=0$ and therefore $I(\tilde{A}) \rightarrow a_{2}$ as $T \rightarrow \infty$.

Note that the factor $\frac{\log (1+T)}{T}$ is called the cloud index(CI).

and the time $T$ is measured by days in practice. The nature of cloud index is shown in Fig. 2.

In general, for practical purpose the time horizon cannot be infinite so after defuzzification the indexed values do not

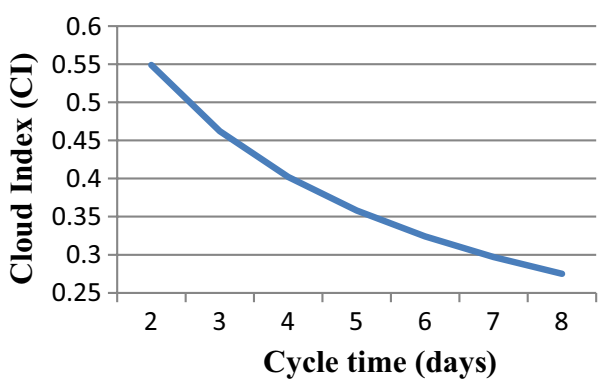

Fig. 2 Nature of Fuzziness over time

come back to its crisp original even the restrictions have been removed in our assumptions.

\section{Inventory process and cloudy fuzzy environment (De and Mahata 2017)}

The measure of fuzziness depends upon what quantities are going to measure. In inventory process, the cycle time is one of the most important decision variable, so it is quite clear that fuzziness might have some relations on elapsed cycle time. In any inventory process, initially the uncertainties viewed are high and as the time progresses everything is began to clear for an inventory practitioner/decision maker (DM). As time progresses, the ambiguities underlying in the inventory system began to remove, and it is experiencing from the very ancient stage of any management system. When the inventory cycle time is low, the ambiguity becomes high and vice versa.

Let us discuss about the ambiguity over the demand rate, a most vital parameter of an inventory process. Here at the beginning the ambiguity over demand rate is high because, the people will usually take much time (no matter what offers have been declared or how attractive the getup of the system be) to accept and adopt the process.

If the cycle time ends prior to the "fully adopted" time period, then the cost becomes high. The basic insight over the public opinion is that 'the system is less reliable' as because the DM is hesitating to run the process for a longer time. This feeling must affects directly to the customers' satisfactions level as well as on demand rate. However, as the cycle time becomes more the customers are began to get more satisfaction. A saturation on adoptability and reliability reaches. So the ambiguities have been removed from the process, and a grand paradigm shift on progress (financial development, cost minimization, achievement of large customer, etc.) of that system has been viewed. 


\section{Problem definition and case study}

In December 2018, a visit has been performed at "Mondal Trading Company Soft Toy" along with a shop situated near Goriahat, Kolkata, India. It is observed that during the production process some items arrive as defective which are in small percentage with respect to the total production. The retailers are purchasing these items in a lot from this company without getting any scope to choice the good items only. After receiving the items in a lot, at the retailer's shop, the screening process to separate the defective items starts and at the same time the sale of good items begins with a fixed selling price. As soon as the whole items have been screened out, the retailer sells these items in a lot with offering some discounts. Moreover, it is noticed that, since the defective items are repairable and they began to look as good as new so by the declaration "items of discounted price" motivates customers to purchase more items. By this time, usually the retailer decides not to get shortage of the items between two consecutive orders. Thus the basic problem is to know:

(1) How much amount of items to be ordered so that shortage will never come?

(2) What will be the inventory run time so as to keep maximum average profit all the time?

The several cost components associated with the retailer's inventory system are studied as follows:

The inventory operation operates on 8 hours/day, so that for 365 days a year, the annual screening rate $x=1 \times 60 \times 8 \times 365=175200$ unit $/$ year $\mathrm{t}[1 \mathrm{unit} / \mathrm{min}]$, screening cost $\lambda=\$ 0.5 /$ unit, yearly demand $d=5000$ units, ordering cost $k=\$ 200 /$ cycle, holding cost per unit item per year $h=\$ 5$, purchase cost $c=\$ 25 /$ unit, selling price of good-quality items $s=\$ 50 /$ unit.

\section{Notation and assumptions}

\section{Assumptions}

The following fundamental assumptions and notation are made for developing the mathematical model in this paper:

(a) Items, received or produced that are not of perfect quality and that are not necessarily defective, could be used in another production/inventory situation.

(b) A lot size is delivered instantaneously with a purchasing price of per unit and an ordering cost for the total lot.

(c) Each lot received contains percentage of defectives with a known probability density function. (d) Good-quality items have a fixed selling price.

(e) Defective items are sold as a single batch at a proportionate discounted price.

(f) $\mathrm{A}$

(g) $100 \%$ screening process of the lot is conducted.

(h) Shortages are not allowed.

(i) Lead time is zero.

\section{Notations}

$y \quad$ Order size, is a decision variable

$d \quad$ Demand rate

$x \quad$ Screening rate, $x>d$

$c \quad$ Unit purchasing price (\$)

$k \quad$ Fixed cost of placing an order $(\$)$

$p \quad$ Percentage of defective items in $y$

$f(p)$ Probability density function of $p$

$s \quad$ Unit selling price of items of good quality (\$)

$\lambda \quad$ Unit screening cost (\$)

$T \quad$ Cycle length (years), is a dependent variable

\section{Formulation of mathematical model}

Let $d$ be the demand rate per unit time of an inventory process. An order of size $y$ is placed whenever the inventory level reaches zero. The items are received instantaneously with a unit purchasing price $c$, fixed ordering cost $k$,and the unit inventory holding cost $h$ per unit time. Each lot received contains percentage defectives. A $100 \%$ screening process of the lot is conducted at a rate of $x$ units per unit time with unit screening cost $\lambda$. After completion of the screening process, items of poor quality are sold as a single batch at proportionate discounted price. However, the price of a good-quality item is $s$ per unit.

The behavior of the inventory level is as shown in Fig. 3, where $T$ is the cycle length, $p y$ is the number of defectives

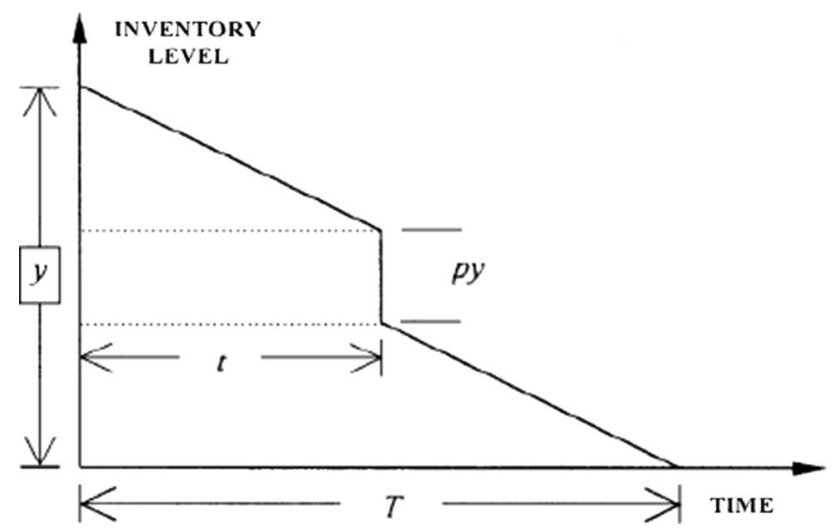

Fig. 3 EOQ model for defective items 
withdrawn from inventory and $t$ is the total screening time of $y$ units per order cycle.

The number of good items in each order is equal to the lot size less defective items,

$y-p y=(1-p) y$.

Under the assumption of Salameh and Jaber (2000), in order to avoid shortages the number of good items, $(1-p) y$ is at least equal to the demand during the screening time $t$ i.e.,

$(1-p) y \geq d t$,

where $d$ is the demand per year or equivalently,

$p \leq 1-\frac{d}{x}$

With the above assumptions, the total cost per cycle for the modified EOQ model for imperfect-quality items is:

$\mathrm{TC}(y)=$ Fixed cost of placing an order + variable cost of lot size + screening cost of lot size + holding cost

$\mathrm{TC}(y)=K+c y+\lambda y+h\left(\frac{y(1-p) T}{2}+\frac{p y^{2}}{x}\right)$

In the proposed model, a proportionate rate of discount is introduced depending on the quality of the imperfect type items. Out of the imperfect type items, the best item is sold with minimum discount. Subsequently, depending on the quality of all other imperfect type items, a proportionate rate of discount has been introduced.

The total revenue per cycle $\operatorname{TR}(y)=$ Total sales volume of (good-quality items + imperfect-quality items).

$\operatorname{TR}(y)=s y(1-p)+\sum_{i=1}^{y p}\left(s-\left(1-\frac{y p-i}{y p}\right)\left(\frac{\operatorname{TR}(y)-\operatorname{TC}(y)}{y}\right)\right)$

The following is the result for $\operatorname{TR}(y)$ obtained after simplification.

$\operatorname{TR}(y)=\frac{2 s y^{2}+K+c y+\lambda y+h\left(\frac{y(1-p) T}{2}+\frac{p y^{2}}{x}\right)(y p+1)}{2 y+(y p+1)}$

Thus, total profit per cycle $=$ Total revenue per cycle-Total cost per cycle.

$$
\begin{aligned}
& \Rightarrow \operatorname{TP}(y)=\operatorname{TR}(y)-\mathrm{TC}(y) \\
& =\left[\frac{2 s y^{2}+\left\{k+c y+\lambda y+h\left(\frac{y(1-p) T}{2}+\frac{p y^{2}}{x}\right)(y p+1)\right\}}{2 y+(y p+1)}\right] \\
& -\left[k+c y+\lambda y+h\left(\frac{y(1-p) T}{2}+\frac{p y^{2}}{x}\right)\right]
\end{aligned}
$$

Since the replenishment cycle length $T=\frac{(1-p) y}{d}$. So, by dividing the total profit per cycle by the cycle length, the total profit per unit time can be written as:

$$
\begin{gathered}
\operatorname{TPU}(y) \frac{\operatorname{TP}(y)}{T}=\frac{2 d}{2 y+y p+1}(s y-k-c y-\lambda y) \\
\left(\frac{1}{1-p}\right)-\frac{h y^{2}}{2 y+y p+1}(1-p)
\end{gathered}
$$

Since $p$ is a random variable with a known probability density function $f(p)$, the expected value of Eq. (17), $\operatorname{ETPU}(y)$, is given as

$$
\begin{aligned}
& \operatorname{ETPU}(y)=\left(\frac{1}{1-E[p]}\right) \\
& {\left[\frac{2 d s y-2 d k-2 d c y-2 d \lambda y}{2 y+y E[p]+1}-\frac{h y^{2}\left(1-(E[p])^{2}\right)}{2 y+y E[p]+1}\right]}
\end{aligned}
$$

The optimality condition meant for the concavity of the expected total profit in per unit time is demonstrated by finding the first derivative of Eq. (18).

$$
\begin{aligned}
\frac{\mathrm{dETPU}(y)}{\mathrm{d} y}= & \left(\frac{1}{1-E[p]}\right)\left(\frac{1}{(2 y+y E[p]+1)^{2}}\right) \\
& {[2 d s-2 d c-2 d \lambda+4 d k+2 d k E[p]} \\
& -2 h y^{2}+2 h y^{2}(E[p])^{2}-h y^{2} E[p] \\
& \left.+h y^{2}(E[p])^{3}-2 h y+2 h y(E[p])^{2}\right]
\end{aligned}
$$

$\frac{\mathrm{d}^{2} \operatorname{ETPU}(y)}{\mathrm{d} y^{2}}$

$$
\begin{aligned}
= & \left(\frac{1}{1-E[p]}\right)\left(\frac{1}{(2 y+y E[p]+1)^{3}}\right) \\
& {[8 d s-8 d c-8 d \lambda+16 d k+16 d k E[p]-4 d s E[p]} \\
& \left.-4 d c E[p]-4 d \lambda E[p]+4 d k(E[p])^{2}+2 h-2 h(E[p])^{2}\right] \leq 0 .
\end{aligned}
$$

The second derivative of $\operatorname{ETPU}(y)$ is negative for all values of $y$ which implies that there exists a unique value of $y^{*}$ that maximizes (18) and it is given as follows:

$y^{*}=\sqrt{\frac{2 d S-2 d c-2 d \lambda+4 d k+2 d k E[p]}{2 h-2 h(E[p])^{2}+h E[p]-h(E[p])^{3}+\frac{2 h}{y}-\frac{2 h}{y}(E[p])^{2}}}$

and 
$T^{*}=\frac{(1-E[p]) y^{*}}{d}$

For large value of $y, \frac{1}{y} \rightarrow 0$ giving

$$
y^{*}=\sqrt{\frac{2 d S-2 d c-2 \lambda d+4 d k+2 d k E[p]}{2 h-2 h(E[p])^{2}+h E[p]-h(E[p])^{3}}}
$$

In addition, when $p=0, \lambda+c=s$, Eq. (21) reduces to the traditional EOQ formulae,

$y=\sqrt{\frac{2 k d}{h}}$.

\section{Numerical Example 1}

Referring to the numerical data obtained from case study a numerical illustration has been done. Also, as per case study, the defective percentage $p$ follows random variable, and it is uniformly distributed with its probability density function as

$f(p)= \begin{cases}25 & 0 \leq p \leq 0.05 \\ 0 & \text { otherwise }\end{cases}$

Utilizing these data in Eqs. (18), (21), and (22), the optimum value of $y$ is given by: $y^{*}=1556$ units, the optimal cycle time is $T^{*}=0.3015$ years, and the maximum profit per year is given as $\operatorname{ETPU}\left(y^{*}\right)=1230057 /$ year.

\section{Comparison with the traditional EPQ/EOQ model}

First of all, for different values of $E[p](0.02 \leq E[p] \leq 0.25$, the basic classical model has been studied. The ratio of $y^{*}$ (modified $\mathrm{EPQ} / \mathrm{EOQ}$ ) to the $y_{\text {trad }}^{*}$ (traditional $\mathrm{EPQ} / \mathrm{EOQ}$ ) is given as,

$\psi=\frac{y^{*}}{y_{\text {trad }}^{*}}=\sqrt{\frac{\left(\frac{s-c-\lambda}{K}\right)+2+E[p]}{2-2(E[p])^{2}+E[p]-(E[p])^{3}}}$

The change in the expected total profit per unit time, $\Omega$, is determined from Eq. (18) and Eq. (26) as $\Omega=\operatorname{ETPU}\left(y^{*}\right)-\operatorname{ETPU}\left(y_{\text {trad }}^{*}\right)$

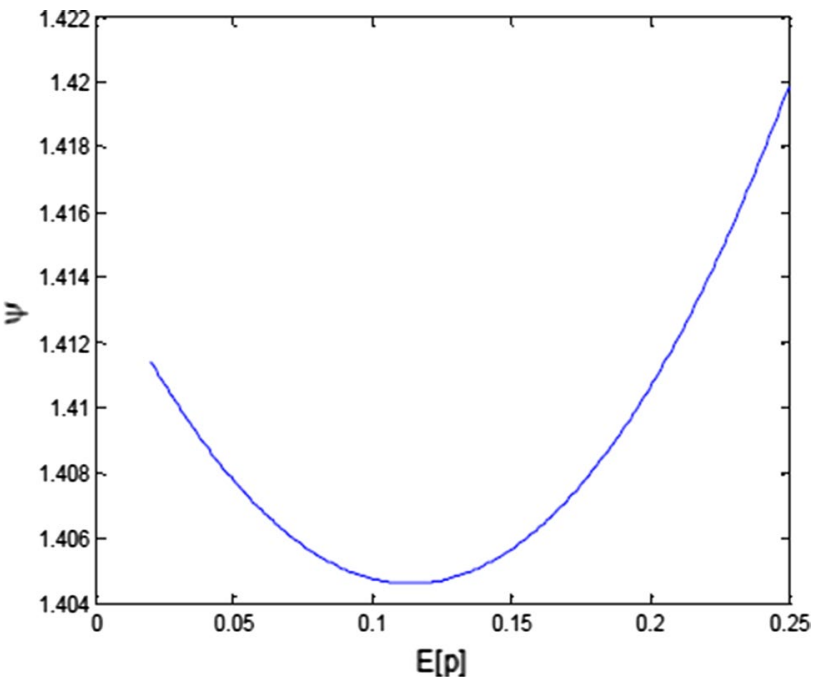

Fig. 4 Behavior of the ratio of modified EPQ/EOQ to the traditional $\mathrm{EPQ} / \mathrm{EOQ}, \psi$, to the increase in the expected value of the number of imperfect-quality items

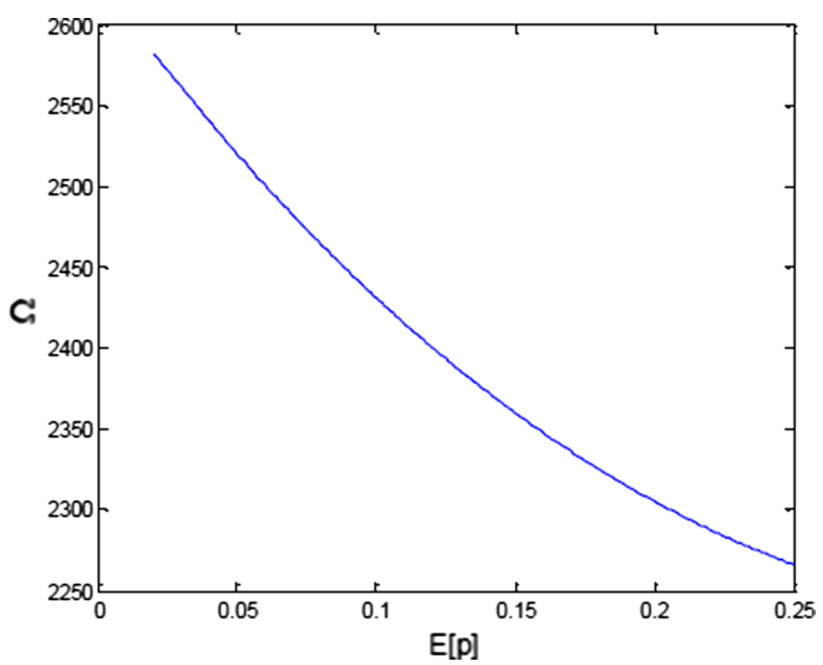

Fig. 5 Behavior of the savings in the expected total profit per unit time of the modified to that of the traditional EPQ/EOQ model to the increase in the expected value of the number of imperfect-quality items

$=\frac{(\psi-1) y_{\text {trad }}^{*}\left[\{2 d(s-c-\lambda+2 k+k E[p])\}+y_{\text {trad }}^{*} h\left\{\left(1-(E[p])^{2}\right)\left(2 y_{\text {trad }}^{*} \psi+y_{\text {trad }}^{*} \psi E[p]+\psi+1\right)\right\}\right]}{\left(2 y_{\text {trad }}^{*}+y_{\text {trad }}^{*} E[p]+1\right)\left(2 y_{\text {trad }}^{*} \psi+y_{\text {trad }}^{*} \psi E[p]+1\right)}$.

The example presented earlier is repeated for different values of $E[p](0.02 \leq E[p] \leq 0.25)$ where the values of $\psi$ and $\Omega$ in Eq. (26) an Eq. (27) respectively, are plotted against those of $E[p]$ as shown in Figs. 4 and 5. It is observed that, for the present situation more units are to be ordered in each lot, i.e., $y^{*} \geq y_{\text {trad }}^{*}$ for $E[p]>0$. Moreover, from Fig. 5, it is observed that low percentage of defective creates more profit as compared to the traditional model, and when this defective percentage goes up, the profit becomes less. 


\section{Comparison with Salameh and Jaber (2000) model}

The optimum lot size in Salameh and Jaber's (2000) model is:

$$
y_{s}^{*}=\sqrt{\frac{2 d k E\left(\frac{1}{1-p}\right)}{h\left[\left(1-E[p]-\frac{2 d}{x}\left(1-E\left(\frac{1}{1-p}\right)\right)\right)\right]}}
$$

So for different values of $E[p](0.02 \leq E[p] \leq 0.25)$ (26) gives

$\psi_{1}=\frac{y_{*}}{y_{s}^{*}}=\sqrt{\frac{\left[\left(\frac{s-c-\lambda}{k}\right)+2+E[p]\right]\left[1-E[p]-\frac{2 d}{x}\left\{1-\left(\frac{1}{1-E[p]}\right)\right\}\right]}{\left(\frac{1}{1-E[p]}\right)\left[2-2(E[p])^{2}+E[p]-(E[p])^{3}\right]}}$

The optimal lot size in proposed model is greater than the lot size in Salameh and Jaber's (2000) model.

The total profit per unit time in Salameh and Jaber's (2000) model is:

$\left\{\begin{array}{l}\text { Maximize } \tilde{z}=\frac{A}{B \tilde{y}+1} \tilde{d} \tilde{y}-\frac{2 k A / \tilde{d}}{B \tilde{y}+1}-\frac{A^{\prime \prime}}{B \tilde{y}+1} \tilde{y}^{2} \\ \text { Where, } \quad A=\left(\frac{2 s-2 c-2 \lambda}{1-E[p]}\right), \quad B=2+E(p), \quad A^{\prime}=1 /(1-(E) \\ \text { Subject to } \tilde{y}=\frac{\tilde{d} T}{1-p}\end{array}\right.$
Now, the membership function of the demand rate $d$ is giv
$\mu(\tilde{d}, T)=\left\{\begin{array}{lll}0 & \text { if } & d\left\langle d_{2}\left(1-\frac{\rho}{1+T}\right) \text { and } d\right\rangle d_{2}\left(1+\frac{\sigma}{1+T}\right) \\ \left\{\frac{d-d_{2}\left(1-\frac{\rho}{1+T}\right)}{\frac{\rho d_{2}}{1+T}}\right\} & \text { if } & d_{2}\left(1-\frac{\rho}{1+T}\right) \leq d \leq d_{2} \\ \left\{\frac{d_{2}\left(1+\frac{\sigma}{1+T}\right)-d}{\frac{\sigma d_{2}}{1+T}}\right\} & \text { if } & d_{2} \leq d \leq d_{2}\left(1+\frac{\sigma}{1+T}\right) \\ \text { for } \quad 0<\rho, \sigma<1\end{array}\right.$

Therefore, using the constraint of (32), the membership function of the fuzzy order quantity $\tilde{y}$ is obtained as

$$
\begin{aligned}
\operatorname{ETPU}\left(y_{s}\right)= & d\left(s-v+\frac{h y}{x}\right)+d\left(v-\frac{h y}{x}-c-\lambda-\frac{k}{y}\right) \\
& E\left[\frac{1}{1-p}\right]-h\left(\frac{y(1-E[p])}{2}\right)
\end{aligned}
$$

The change in the expected total profit per unit time, $\Omega_{1}$ is determined from (18) and (26) as;

$$
\begin{aligned}
\Omega_{1}= & \operatorname{ETPU}\left(y_{s}\right)-\operatorname{ETPU}(y) \\
= & \frac{1}{1-E[p]}\left[\left\{\frac{2 d s y-2 d k-2 d c y-2 d \lambda y}{2 y+y E[p]+1}-\frac{h y^{2}\left[1-(E[p])^{2}\right]}{2 y+y E[p]+1}\right\}\right. \\
& \left.-d\left(v-\frac{h y}{x}-c-\lambda-\frac{k}{y}\right)\right] \\
& -d\left(s-v+\frac{h y}{x}\right)+h\left(\frac{y(1-E[p])}{2}\right)
\end{aligned}
$$

\section{Fuzzy mathematical model}

Let us assume the demand rate $d$ for the above proposed model behaves a cloud-type fuzzy number. Since the amount of perfect items $y$ is functionally related to the demand rate so from Eq. (18), the fuzzy problem becomes

$\mu(\tilde{y}, T)=\left\{\begin{array}{lll}0 & \text { if } & \frac{(1-p) y}{T}\left\langle d_{2}\left(1-\frac{\rho}{1+T}\right) \text { and } \frac{(1-p) y}{T}\right\rangle d_{2}\left(1+\frac{\sigma}{1+T}\right) \\ \left\{\begin{array}{ll}\frac{(1-p) y}{T}-d_{2}\left(1-\frac{\rho}{1+T}\right) \\ \frac{\rho d_{2}}{1+T}\end{array}\right\} & \text { if } & d_{2}\left(1-\frac{\rho}{1+T}\right) \leq \frac{(1-p) y}{T} \leq d_{2} \\ \left\{\begin{array}{ll}d_{2}\left(1+\frac{\sigma}{1+T}\right)-\frac{(1-p) y}{T} \\ \frac{\sigma a_{2}}{1+T}\end{array}\right\} & \text { if } & d_{2} \leq \frac{(1-p) y}{T} \leq d_{2}\left(1+\frac{\sigma}{1+T}\right)\end{array}\right.$ 


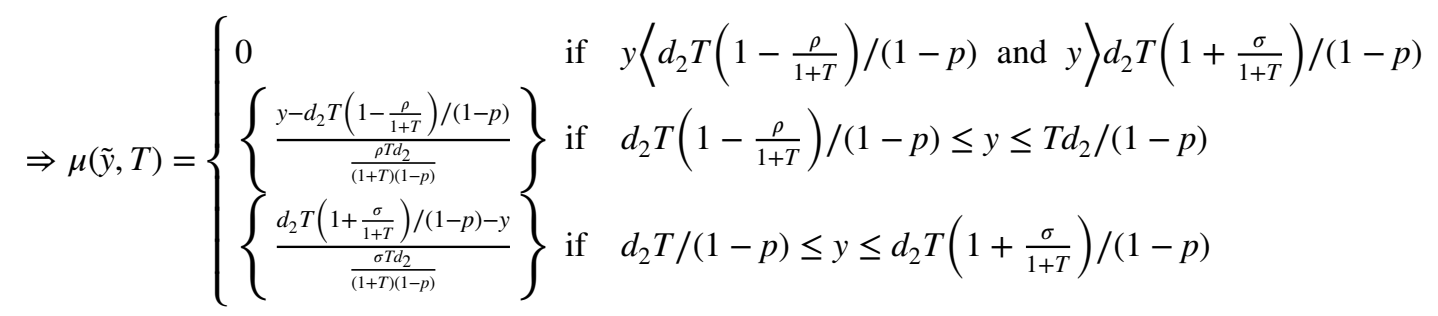

Moreover, the $\alpha$-cuts of $\mu(\tilde{d}, T)$ and $\mu(\tilde{y}, T)$ are obtained by using (33) and (34), and they can be put as $\left[d_{2}\left(1-\frac{\rho}{1+T}\right)+\frac{\alpha \rho d_{2}}{1+T}, d_{2}\left(1+\frac{\sigma}{1+T}\right)-\frac{\alpha \sigma d_{2}}{1+T}\right] \quad$ a n d $\left[\frac{d_{2} T}{1-p}\left(1-\frac{\rho}{1+T}\right)+\frac{\alpha \rho T d_{2}}{(1+T)(1-p)}, \frac{d_{2} T}{1-p}\left(1+\frac{\sigma}{1+T}\right)-\frac{\alpha \sigma T d_{2}}{(1+T)(1-p)}\right]$, respectively.

Thus, the corresponding index value of $\tilde{y}$ and $\tilde{d}$ are obtained as

$$
\begin{aligned}
I(\tilde{y})= & \frac{1}{2 \tau} \int_{T=0}^{\tau} \int_{\alpha=0}^{1}\left[\frac{d_{2} T}{1-p}\left(1-\frac{\rho}{1+T}\right)+\frac{\alpha \rho T d_{2}}{(1+T)(1-p)}\right. \\
& \left.+\frac{d_{2} T}{1-p}\left(1+\frac{\sigma}{1+T}\right)-\frac{\alpha \sigma T d_{2}}{(1+T)(1-p)}\right] \mathrm{d} \alpha \mathrm{d} T \\
= & \frac{1}{2 \tau(1-p)} \int_{T=0}^{\tau}\left[d_{2} T\left(1-\frac{\rho}{1+T}\right)+\frac{\rho T d_{2}}{2(1+T)}\right. \\
& \left.+d_{2} T\left(1+\frac{\sigma}{1+T}\right)-\frac{\sigma T d_{2}}{2(1+T)}\right] \mathrm{d} T \\
= & \frac{d_{2}}{2 \tau(1-p)} \int_{T=0}^{\tau}\left[2 T-\frac{(\rho-\sigma) T}{2(1+T)}\right] \mathrm{d} T \\
= & \frac{d_{2}}{2 \tau(1-p)}\left[\tau^{2}+\frac{(\rho-\sigma)}{2}\{\log |1+\tau|-\tau\}\right] \\
= & \frac{d_{2}}{2(1-p)}\left[\tau-\frac{(\rho-\sigma)}{2}\left\{1-\frac{\log |1+\tau|}{\tau}\right\}\right]
\end{aligned}
$$

and

Therefore utilizing $(32)$ and using $(35,36)$ the index value of the fuzzy objective function is given by

$$
\begin{aligned}
I(\tilde{z})= & I\left[\frac{1}{B \tilde{y}+1}\left\{A \tilde{d} \tilde{y}-2 k A^{\prime} \tilde{d}-A^{/ /} \tilde{y}^{2}\right\}\right] \\
= & I\left(\frac{1}{B \tilde{y}+1}\right)\left[I(\tilde{d}) I\left(A \tilde{y}-2 k A^{\prime}\right)-A^{/ /} I\left\{\tilde{y}^{2}\right\}\right] \\
= & {\left[\frac{1}{B I(\tilde{y})+1}\right]\left[I(\tilde{d})\left\{A I(\tilde{y})-2 k A^{\prime}\right\}-A^{/ /}\{I(\tilde{y})\}^{2}\right] } \\
= & {\left[\frac{1}{\frac{d_{2} B}{(1-p)}\left[\frac{\tau}{2}-\frac{(\rho-\sigma)}{4}\left\{1-\frac{\log |1+\tau|}{\tau}\right\}\right]+1}\right] } \\
& \times\left[d_{2}\left[1+\frac{(\rho-\sigma)}{4}\left\{1-\frac{\log |1+\tau|}{\tau}\right\}\right]\right. \\
& {\left[\frac{d_{2} A}{(1-p)}\left[\frac{\tau}{2}-\frac{(\rho-\sigma)}{4}\left\{1-\frac{\log |1+\tau|}{\tau}\right\}\right]\right] } \\
& \left.-\frac{A^{/ /} d_{2}^{2}}{(1-p)^{2}}\left[\frac{\tau}{2}-\frac{(\rho-\sigma)}{4}\left\{1-\frac{\log |1+\tau|}{\tau}\right\}\right]^{2}\right]
\end{aligned}
$$

Particular Cases

(1) If $\quad(\rho-\sigma) \rightarrow 0 \quad$ the n $\quad I(\tilde{z}) \rightarrow\left[\frac{1}{\frac{d_{2} B}{(1-p)}\left[\frac{\tau}{2}\right]+1}\right] \times$ $\left[d_{2}\left[\begin{array}{c}\frac{d_{2} A}{(1-p)}\left[\frac{\tau}{2}\right] \\ -2 k A^{\prime}\end{array}\right]-\frac{A^{\prime /} d_{2}^{2}}{(1-p)^{2}}\left[\frac{\tau}{2}\right]^{2}\right]$

$$
\begin{aligned}
I(\tilde{d}) & =\frac{d_{2}}{2 \tau} \int_{T=0}^{\tau} \int_{\alpha=0}^{1}\left[\left(1-\frac{\rho}{1+T}\right)+\frac{\alpha \rho}{(1+T)}+\left(1+\frac{\sigma}{1+T}\right)-\frac{\alpha \sigma}{(1+T)}\right] \mathrm{d} \alpha \mathrm{d} T \\
& =\frac{d_{2}}{2 \tau} \int_{T=0}^{\tau}\left[2+\frac{\sigma-\rho}{2(1+T)}\right] \mathrm{d} T=d_{2}\left[1+\frac{(\rho-\sigma)}{4}\left\{1-\frac{\log |1+\tau|}{\tau}\right\}\right]
\end{aligned}
$$

Table 1 Optimal solution for the imperfect EOQ model

\begin{tabular}{lclll}
\hline Model & $T^{*}$ (days) & $y^{*}($ Unit $)$ & $z_{*}(\$)$ & $\mathrm{CI}=\frac{\log \left|1+T^{*}\right|}{T^{*}}$ \\
\hline Crisp & 90 & 651.406 & 122465.80 & \\
General fuzzy & 46 & 643.205 & 119362.80 & 0.0840 \\
Cloudy fuzzy & 101 & 720.38 & 122816.4 & 0.0454 \\
\hline
\end{tabular}

$\Rightarrow\left[\frac{1}{B y+1}\right] \times\left[d\left(A y-2 k A^{\prime}\right)-A^{/ /} y^{2}\right] \Rightarrow z$, which is similar to crisp objective function. 
Table 2 Sensitivity analysis of the imperfect cloudy fuzzy EOQ model

\begin{tabular}{|c|c|c|c|c|c|c|}
\hline Parameters & $\%$ change & $T^{*}$ (Days) & $y^{*}$ (Unit) & $z^{*}(\$)$ & $\mathrm{RC}=\frac{z^{*}-z_{*}}{z_{*}} \times 100 \%$ & $\mathrm{CI}=\frac{\log \left|1+T^{*}\right|}{T^{*}}$ \\
\hline \multirow[t]{4}{*}{$d_{0}$} & +50 & 84 & 887.830 & 185260.5 & +51.07 & 0.0529 \\
\hline & +30 & 90 & 824.751 & 160335.5 & +30.75 & 0.0502 \\
\hline & -30 & 121 & 599.137 & 85691.02 & -30.12 & 0.0396 \\
\hline & -50 & 143 & 503.365 & 60889.55 & -50.35 & 0.0349 \\
\hline \multirow[t]{4}{*}{$\rho$} & +50 & 137 & 927.337 & 123839.8 & +0.99 & 0.0360 \\
\hline & +30 & 121 & 830.442 & 123466.8 & +0.68 & 0.0398 \\
\hline & -30 & 88 & 640.738 & 122562.5 & -0.05 & 0.0510 \\
\hline & -50 & 81 & 599.444 & 122314.9 & -0.26 & 0.0540 \\
\hline \multirow[t]{4}{*}{$\sigma$} & +50 & 86 & 624.323 & 122467.1 & -0.13 & 0.0521 \\
\hline & +30 & 92 & 658.411 & 122661.3 & +0.03 & 0.0495 \\
\hline & -30 & 115 & 799.378 & 123337.5 & +0.58 & 0.0412 \\
\hline & -50 & 126 & 864.252 & 123601.6 & +0.79 & 0.0384 \\
\hline \multirow[t]{4}{*}{$p$} & +50 & 100 & 722.634 & 124863.1 & +1.82 & 0.0460 \\
\hline & +30 & 101 & 721.662 & 124093.4 & +1.2 & 0.0459 \\
\hline & -30 & 104 & 719.306 & 121914.1 & -0.58 & 0.0450 \\
\hline & -50 & 105 & 718.703 & 121229.0 & -1.14 & 0.0440 \\
\hline \multirow[t]{4}{*}{$h$} & +50 & 81 & 570.295 & 122205.9 & -0.34 & 0.0540 \\
\hline & +30 & 88 & 618.550 & 122494.4 & -0.11 & 0.0511 \\
\hline & -30 & 125 & 894.138 & 123562.2 & +0.76 & 0.0383 \\
\hline & -50 & 157 & 1109.482 & 124044.1 & +1.16 & 0.0322 \\
\hline \multirow[t]{4}{*}{$\lambda$} & +50 & 102 & 719.390 & 121693.3 & -0.76 & 0.0450 \\
\hline & +30 & 102 & 719.787 & 122208.0 & -0.34 & 0.0450 \\
\hline & -30 & 102 & 720.974 & 123751.9 & +0.92 & 0.0454 \\
\hline & -50 & 102 & 721.371 & 124266.6 & +1.34 & 0.0453 \\
\hline \multirow[t]{4}{*}{$k$} & +50 & 123 & 868.140 & 122364.3 & -0.13 & 0.0390 \\
\hline & +30 & 115 & 812.520 & 122597.2 & -0.03 & 0.0413 \\
\hline & -30 & 87 & 613.338 & 123419.7 & +0.65 & 0.0515 \\
\hline & -50 & 75 & 529.062 & 123761.8 & +0.93 & 0.0577 \\
\hline \multirow[t]{4}{*}{$c$} & +50 & 95 & 673.484 & 58655.8 & -52.17 & 0.0480 \\
\hline & +30 & 98 & 691.642 & 84383.83 & -31.19 & 0.0470 \\
\hline & -30 & 106 & 751.067 & 161581.1 & +31.76 & 0.0440 \\
\hline & -50 & 109 & 772.692 & 187318.1 & +52.75 & 0.0430 \\
\hline \multirow[t]{4}{*}{$s$} & +50 & 118 & 831.242 & 251671.2 & +105.27 & 0.0410 \\
\hline & +30 & 111 & 783.786 & 200187.5 & +63.25 & 0.0420 \\
\hline & -30 & 94 & 664.689 & 45792.57 & -62.66 & 0.0480 \\
\hline & -50 & No... & Feasible.. & Solution. & $\ldots$ & $\ldots$ \\
\hline
\end{tabular}

\section{Numerical Example 2}

In our proposed fuzzy model, let $d=5000,=100$, $h=5, \lambda=0.5, c=25, s=50, p=0.05$ for crisp solution and for fuzzy solution assume $\rho=0.4, \sigma=0.3$ and $\tilde{d}=\langle 5000(1-\rho), 5000,5000(1+\sigma)\rangle$. Keeping the other parameters as fixed stated above. The optimal results are put in Table 1.

\section{Sensitivity analysis}

The sensitivity analysis of the objective function with respect to the changes of each of the parameters $\left\{d_{0}, p, k\right.$, $h, \lambda, c, s\}$ from -50 to $+50 \%$ are stated in Table 2 . 


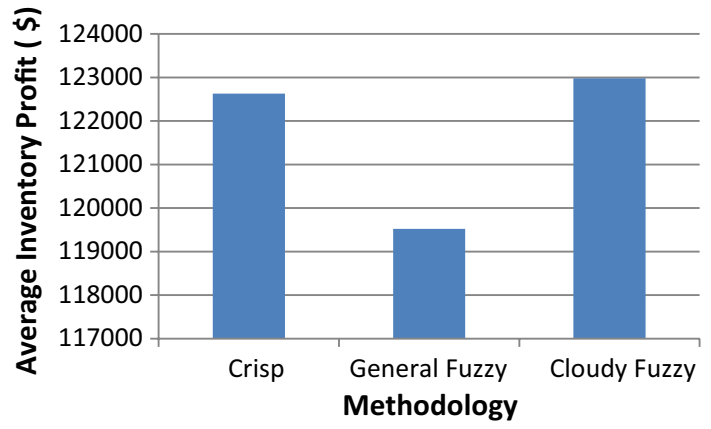

Fig. 6 Inventory cost vs methodology

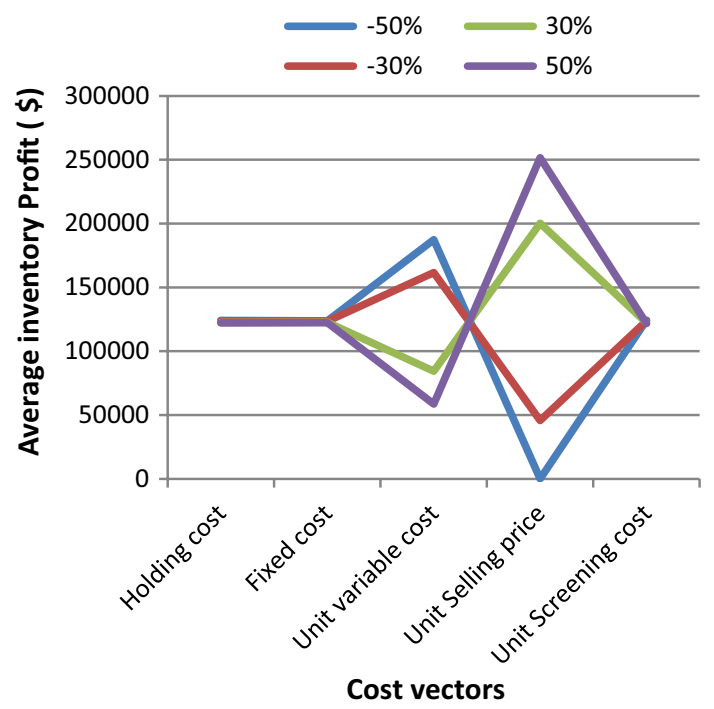

Fig. 7 Inventory profit vs variation of cost vectors

\section{Discussion on sensitivity analysis}

From the sensitivity analysis Table 2 , it is seen that the parameters like the initial demand $d_{0}$, the unit purchasing price $c$, and the unit selling price $s$ are highly sensitive parameters. The range of these changes assumes values between -62.66 and $+105 \%$ as a whole. The other parameters have negligible effect on the proposed model for the changes of the parameters $\{\rho, \sigma, p, k, h, \lambda\}$ within -50 to $+50 \%$. Also the study reveals that for the case of highly sensitive parameters the optimum cycle time varies within the range 84-118 days with respect to the variation of maximum order quantity $831.242-887.830$ units. Throughout the whole table, the minimum cloud index (0.0322) appears whenever the parameter $h$ has been changed to $-50 \%$, but for cloud index $0.0410(>0.0322)$ the profit curve assumes value 1.05 times with respect to the crisp optimum.

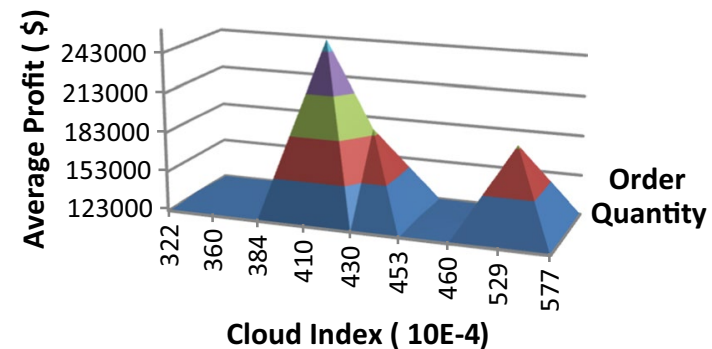

Fig. 8 Average profit vs order quantity under several cloud index

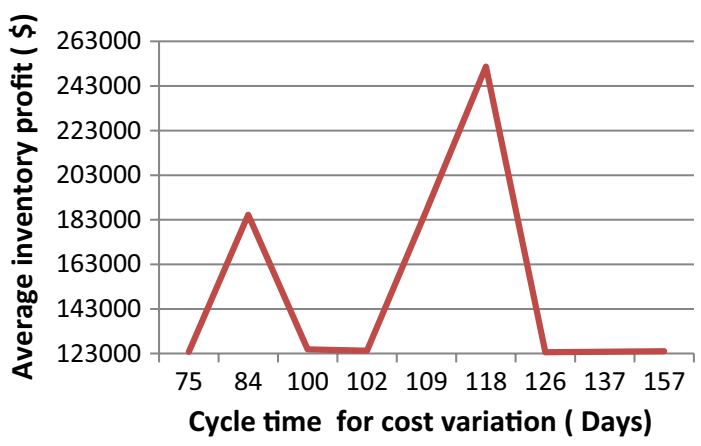

Fig. 9 Inventory profit vs cycle time

\section{Graphical illustrations}

Here several graphs have been drawn using the numerical results obtained from the proposed model. Figure 6 shows the trends of average profit maximization due to cloudy fuzzy model, the results of general fuzzy model is inferior than those of crisp as well as cloudy fuzzy models. Figure 7 reveals a beautiful flower type figure that corresponds the behavior of the profit function over the changes of the cost parameters on and from ( -50 to $+50 \%$ ) exclusively. It is seen that the change of holding cost did not give a considerable effect on profit function. But for fixed cost and unit selling price, the profit function gets monotonic increasing and decreasing, respectively, and vice versa within the specific range of the parameters. Moreover, the variation of the unit variable cost and unit screening cost shows that the profit value of the model gets almost same. Figure 8 explores the variation of the average profit function with respect to the variation of the order quantity of perfect items over different cloud index. Also, for the lesser fuzziness intervals (322-384) $10^{-4}$ and (453-460) $10^{-4}$, the profit value assumes almost same. But for the range of fuzziness (384-453) $10^{-4}$ and (460-577) $10^{-4}$, the profit function itself gets pyramid type curves. Near 0.041 fuzzy measure, the profit value gets maximum value with highest 
peak but near 0.043 and 0.0529 gets lower peaks. Figure 9 indicates that at 109 days cycle time the model gives maximum profit value with respect to the profit value obtained within the cycle time duration (75-84) days. The other cases give the objective value near $\$ 123,000$ exclusively.

\section{Conclusion}

Cloudy fuzzy system is the latest enriched and established methodology in the fuzzy literature, but yet no such article has been studied in this direction. Basically, this paper has focused the novel application of new defuzzification method studies over the EOQ model with imperfect items developed by Salameh and Jaber (2000). Moreover, the model has been discussed over crisp, general fuzzy, and cloudy fuzzy environment exclusively. Numerical study reveals the superiority of the cloudy fuzzy environment with respect to that of general fuzzy model. The managerial insights are observed as follows:

(1) Cloudy fuzzy model always gives average maximum profit value of the model.

(2) Lesser ambiguities (less fuzziness) do not mean more profit of the model.

(3) All cost parameters are not similarly responsible for the enhancement of profit curve.

(4) Choice of perfect order quantity and the specific cycle time can change the overall decision of an inventory process.

Acknowledgements The authors are thankful to the anonymous reviewers for their valuable suggestions to improve the quality of the article.

\section{Compliance with ethical standards}

Conflict of interest The authors declare that there is no conflict of interest regarding the publication of the article.

Open Access This article is distributed under the terms of the Creative Commons Attribution 4.0 International License (http://creativeco mmons.org/licenses/by/4.0/), which permits unrestricted use, distribution, and reproduction in any medium, provided you give appropriate credit to the original author(s) and the source, provide a link to the Creative Commons license, and indicate if changes were made.

\section{References}

Aghili SJ, Hoseinabadi HH (2017) Reliability evaluation of repairable systems using various fuzzy-based methods - a substation automation case study. Int J Electr Power Energy Syst 85:130-142
Ben-Daya M (1999) Multi-stage lot sizing models with imperfect processes and inspection errors. Product Plan Control 10(2):118-126

Cárdenas-Barrón LE (2009) Economic production quantity with rework process at a single-stage manufacturing system with planned backorders. Comput Ind Eng 57(3):1105-1113

Chakraborty D, Jana DK, Roy TK (2015) Multi-item integrated supply chain model for deteriorating items with stock dependent demand under fuzzy random and bifuzzy environments. Comput Ind Eng $88: 166-180$

Chan WM, Ibrahim RN, Lochert PB (2003) A new EPQ model: integrating lower pricing, rework and reject situations. Product Plan Control 14(7):588-595

Cheng CE (1991) An economic order quantity model with demanddependent unit production cost and imperfect production processes. IIE Trans 23(1):23

Das BC, Das B, Mondal SK (2015) An integrated production inventory model under interactive fuzzy credit period for deteriorating item with severalmarkets. Appl Soft Comput 28:453-465

De SK, Beg I (2016a) Triangular dense fuzzy sets and new defuzzification methods. Int J Intell Fuzzy Syst 31(1):469-477

De SK, Beg I (2016b) Triangular dense fuzzy Neutrosophic sets. Neutrosophic Sets Syst 13:1-12

De SK, Mahata GC (2017) Decision of a fuzzy inventory with fuzzy backorder model under cloudy fuzzy demand rate. Int J Appl Comput Math 3(3):2593-2609

De SK, Sana SS (2013) Fuzzy order quantity inventory model with fuzzy shortage quantity and fuzzy promotional index. Econ Model $31: 351-358$

De SK, Sana SS (2015) Backlogging EOQ model for promotional effort and selling price sensitive demand- an intuitionistic fuzzy approach. Ann Oper Res 233(1):57-76

De SK, Sana SS (2016) The (p,q,r,l) model for stochastic demand under intuitionistic fuzzy aggregation with bonferroni mean. J Intell Manuf 29(8):1753-1771

De SK, Goswami A, Sana SS (2014) An interpolating by pass to Pareto optimality in intuitionistic fuzzy technique for a EOQ model with time sensitive backlogging. Appl Math Comput 230:664-674

Eroglu A, Ozdemir G (2007) An economic order quantity model with defective items and shortages. Int J Prod Econ 106(2):544-549

Gerchak Y, Vickson RG, Parlar M (1988) Periodic review production models with variable yield and uncertain demand. IIE Trans 20(2):144-150

Gholizadeh AA, Shekarian E (2012) A new approach on housing choice using fuzzy logic. TAHGHIGHAT-E-EGHTESADI 47:65-84

Goyal SK, Cárdenas-Barrón LE (2002) Note on: economic production quantity model for items with imperfect quality-a practical approach. Int J Prod Econ 77(1):85-87

Harris FW (1913) Operations and costs (Factory Management Series). A. W. Shaw Co, Chicago, pp 18-52

Jaber MY, Zanoni S, Zavanella LE (2014) Economic order quantity models for imperfect items with buy and repair options. Int J Prod Econ 155:126-131

Kahraman C, Gülbay M, Kabak Ö (2006) Applications of fuzzy sets in industrial engineering: a topical classification. In: Kahraman C (ed) Fuzzy applications in industrial engineering. Springer, Berlin, pp 1-55

Karlin S (1958) One stage inventory models with uncertainty. In: Arrow KJ, Karlin S, Scarf H (eds) Studies in the Mathematical Theory of Inventory and Production. Stanford University Press, Stanford

Karmakar S, De SK, Goswami A (2015) A deteriorating EOQ model for natural idle time and imprecised demand: Hesitant fuzzy approach. Int J Syst Sci Oper Logist. https://doi. org/10.1080/23302674.2015.1087070 
Karmakar S, De SK, Goswami A (2017) A pollution sensitive dense fuzzy economic production quantity model with cycle time dependent production rate. J Clean Prod 154:139-150

Kazemi N, Abdul-Rashid SH, Ghazilla RAR, Shekarian E, Zanoni S (2018) Economic order quantity models for items with imperfect quality and emission considerations. Int J Syst Sci Oper Logist 5(2):99-115

Khan M, Jaber MY, Guiffrida AL, Zolfaghari S (2011) A review of the extensions of a modified EOQ model for imperfect quality items. Int J Prod Econ 132(1):1-12

Kumar RS, Goswami A (2015) EPQ model with learning consideration, imperfect production and partial backlogging in fuzzy random environment. Int J Syst Sci 46:1486-1497

Lee HL, Rossenblatt MJ (1987) Simultaneously determination of production cycles and inspection schedules in a production system. Manage Sci 33:1125-1137

Maddah B, Jaber MY (2008) Economic order quantity for items with imperfect quality: revisited. Int J Prod Econ 112(2):808-815

Mahata GC (2017) A production-inventory model with imperfect production process and partial backlogging under learning considerations in fuzzy random environments. J Intell Manuf 28(4):883-897

Mahata GC, Goswami A (2013) Fuzzy inventory models for items with imperfect quality and shortage backordering under crisp and fuzzy decision variables. Comput Ind Eng 64:190-199

Mondal M, Maity AK, Maiti MK, Maiti M (2013) A production-repairing inventory model with fuzzy rough coefficients under inflation and time value of money. Appl Math Model 37(5):3200-3215

Pal S, Mahapatra GS (2017) A manufacturing-oriented supply chain model for imperfect quality with inspection errors, stochastic demand under rework and shortages. Comput Ind Eng 106:299-314

Papachristos S, Konstantaras I (2006) Economic ordering quantity models for items with imperfect quality. Int J Prod Econ 100(1):148-154

Porteus EL (1986) optimal lot sizing, process quality improvement and setup cost reduction. Oper Res 34:137-144

Rezaei J (2005) Economic order quantity model with backorder for imperfect quality items. In: Proceeding of IEEE international engineering management conference, pp 466-470
Rossenblatt MJ, Lee HL (1986) Economic production cycles with imperfect production processes. IIE Trans 18:48-55

Salameh MK, Jaber MY (2000) Economic production quantity model for items with imperfect quality. Int J Prod Econ 64:59-64

Sarkar B (2012) An EOQ model with delay in payments and stock dependent demand in the presence of imperfect production. Appl Math Comput 218(17):8295-8308

Shekarian E, Gholizadeh AA (2013) Application of adaptive network based fuzzy inference system method in economic welfare. Knowl Based Syst 39:151-158

Shekarian E, Abdul-Rashid SH, Olugu EU (2016a) An integrated fuzzy VIKOR method for performance management in healthcare. In: Tavana M, Szabat K, Puranam K (eds) Organizational productivity and performance measurements using predictive modeling and analytics. IGI Global, Pennsylvania, pp 40-61

Shekarian E, Olugu EU, Abdul-Rashid SH, Kazemi N (2016b) An economic orderquantity model considering different holding costs for imperfect qualityitems subject to fuzziness and learning. J Intell Fuzzy Syst 30:2985-2997

Shekarian E, Olugu EU, Abdul-Rashid SH, Bottani E (2016c) A fuzzy reverselogistics inventory system integrating economic order/production quantitymodels. Int J Fuzzy Syst 18(6):1141-1161

Taleizadeh AA, Noori-daryan M (2015) Pricing, inventory and production policies in a supply chain of pharmacological products with rework process: a game theoretic approach. Oper Res Int J 54(9):2807-2836

Taleizadeh AA, Noori-daryan M, Tavakkodli-Moghaddam R (2015) Pricing and ordering decisions in a supply chain with imperfect quality items and inspection under a buyback contract. Int J Prod Res 53(15):4553-4582

Taleizadeh AA, Khanbaglo MPS, Cárdenas-Barrón LE (2016) An EOQ inventory model with partial backordering and reparation of imperfect products. Int J Prod Econ 182:418-434

Urban TL (1992) Deterministic inventory models incorporating marketing decisions. Comput Ind Eng 22(1):85-93

Wilson RH (1934) A scientific routine for stock control. Harvard Bus Rev 13(1):116-128

Yager R (1981) A procedure for ordering fuzzy subsets of the unit interval. Inf Sci 24(2):143-161

Zadeh LA (1965) Fuzzy sets. Inf Control 8(3):338-353 